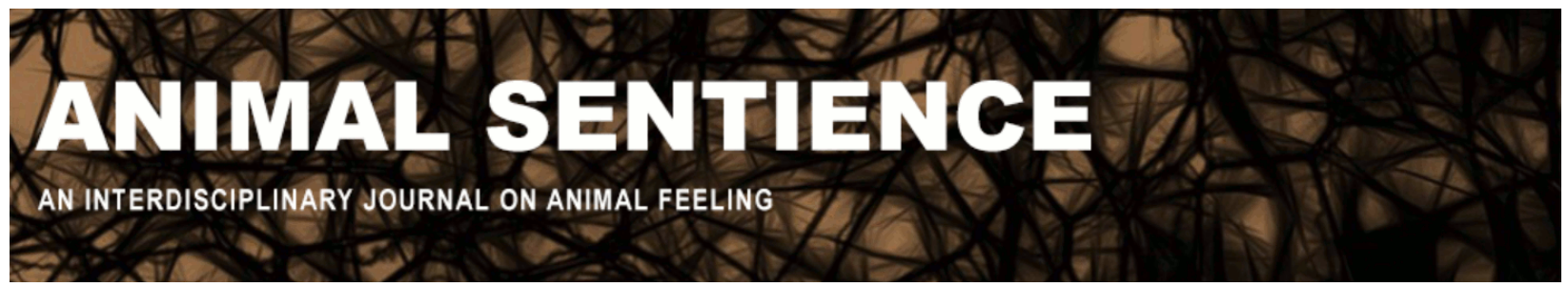

Ball, Derek and Sachs, Benjamin (2019) Scepticism about moral superiority. Animal Sentience 23(46)

DOI: $10.51291 / 2377-7478.1432$

Date of submission: 2019-04-15

Date of acceptance: 2019-05-10

(c)

This article has appeared in the journal Animal

Sentience, a peer-reviewed journal on animal

cognition and feeling. It has been made open access,

free for all, by WellBeing International and deposited

in the WBI Studies Repository. For more information,

please contact

wbisr-info@wellbeingintl.org.

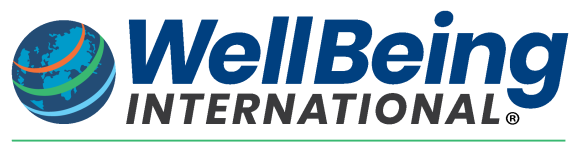

SOLUTIONS FOR PEOPLE, ANIMALS AND ENVIRONMENT 


\title{
Scepticism about moral superiority
}

Commentary on Chapman \& Huffman on Human Difference

\author{
Derek Ball \& Benjamin Sachs \\ Department of Philosophy \\ University of St Andrews
}

\begin{abstract}
Chapman \& Huffman suggest that we might change people's behavior toward animals by resisting an argument that because humans are intellectually superior to animals, they are also morally superior to animals. C \& $\mathrm{H}$ try to show that the premise is false: Humans are not intellectually superior. Several commentators have resisted this response. We suggest that there are other ways of attacking the argument: The notion of moral superiority on which the argument relies is dubious, and the obvious ways of reformulating the argument are instances of the "naturalistic fallacy."
\end{abstract}

Derek Ball, Senior Lecturer in Philosophy, University of St Andrews, does research on philosophy of mind and philosophy of language. Co-editor of The Science of Meaning (OUP 2018), he is currently writing a book about metasemantics. Website

Benjamin Sachs, Senior Lecturer in Philosophy, University of St. Andrews, does research on applied ethics, coercion, political philosophy, and philosophy of law. The author of Explaining Right and Wrong (2018), he is currently writing a book arguing for contractarianism as a political morality. Website
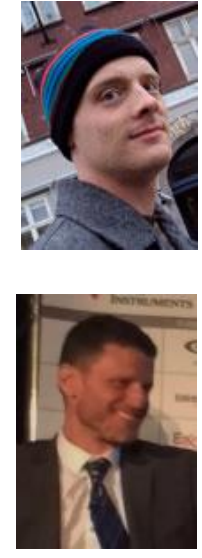

Chapman \& Huffman (2018) (C \& H) aim to promote better treatment of non-human animals and the preservation of biodiversity by rebutting an argument that they think has been used to "justify human cruelty" (p. 4). A simple version of the argument would run as follows:

Premise: Humans are intellectually superior to non-human animals.

Conclusion 1: Therefore, humans are morally superior to animals.

Conclusion 2: Therefore, it is morally permissible for humans to (e.g.) kill animals, destroy their habitat, and so on.

There are several lines of response to this argument in $\mathrm{C} \& \mathrm{H}^{\prime} \mathrm{s}$ target article, but perhaps the most prominent is that the premise is false: "Many human traits once thought unique to our species have proved to differ only in degree from those of many other species living on the planet." C \& H claim that recognising the continuity between humans and other animals "will allow us to make decisions - such as whether to use palm oil or how high on the food chain to eat - with a realistic understanding of the consequences of our actions, for them as well as for us." This will hence presumably change our behaviour. 
Let's suppose that $\mathrm{C} \& \mathrm{H}$ are right: something like this argument does underlie much thinking about animals; so, responding to it is a good way to motivate the kinds of change in our behaviour that $\mathrm{C} \& \mathrm{H}$ persuasively suggest are necessary. There are still important questions about rhetorical strategy: What is the best way to rebut the argument? What response is most likely to convince people to reject the argument and change their behaviour? C \& $\mathrm{H}$ question the premise; but many commentators have called their reasoning into question, with several expressing the opinion that it is "obvious" ( $\mathrm{Ng} 2019$ ) that humans are in some sense intellectually superior (Juergens 2018, lotchev and Costa 2019, Johansen 2019, Paez 2019, Vonk 2019, Wilson and Lehman 2019, Woodruff 2019). We are inclined to think that these commentators have a point; but even if they are wrong, the fact that many people are so attracted to this thought shows that $\mathrm{C} \& \mathrm{H}^{\prime}$ s strategy for responding to the argument may not succeed, and that it is worth looking for alternatives.

One possibility is to call into question the notion of moral superiority on which the argument relies. What sort of thing is moral superiority? The superiority of one thing to another is always a matter of the extent to which the two things possess some gradable quality. For example, we might regard one car as superior to another if it accelerates more quickly. In that case, we would be comparing the two cars with respect to their respective abilities to accelerate; and the ability to accelerate is a quality that a car can have to a greater or a lesser extent. Alternatively, we might regard one car as superior to another if it is cheaper. In that case, we would be comparing the two cars with respect to their respective low prices; and low price is a quality that a car can have to a greater or lesser extent.

If the idea of moral superiority makes any sense, there must be a gradable moral quality; that is, a quality that individuals can have to a greater or lesser extent, and the extent to which they have it determines how they must and may be treated. We suggest that it is by no means clear that there is any such quality (Sachs 2011, 2018).

True, some traditional views in moral philosophy endorsed the idea of moral qualities of this kind. For example, the "Great Chain of Being" (GCB) - a once-popular understanding of God's ordering of nature - could be understood as proposing that the gradable moral quality is belovedness-by-God. But we take it that few now would want to endorse the theological burdens of the GCB. In any case, if moral superiority is based on the GCB, then the argument fails unless God loves things precisely to the extent that they are intelligent. So, if we reject the GCB, then we need to look for an alternative gradable moral quality. It is just not clear what such a quality could be.

It would be possible simply to define the notion of moral superiority in terms of what actions are permissible or impermissible. For example, we might simply stipulate that $\mathrm{x}$ is morally superior to $y$ if it is morally permissible for $x$ to kill $y$, destroy $y^{\prime} s$ habitat, and so on. But if we do this, it is obvious that Conclusion 1 (humans are morally superior to animals) plays no role in the argument. In that case, the argument could be restated more concisely like this:

Premise: Humans are intellectually superior to animals.

Conclusion: Therefore, it is morally permissible for humans to (e.g.) kill animals, destroy their habitat, and so on. 
Restating the argument this way reveals it for what it is: an instance of the naturalistic fallacy (i.e., trying to derive what is right and wrong from facts of nature) (Sinclair 2018), in that it purports to derive a normative claim - in this case a claim about what is morally permissible or morally required - from purely non-normative premises. The past three centuries of moral philosophy suggest that no such argument can be valid (Hume 1739/2000: Book 3, Part 1).

We therefore agree with $\mathrm{C} \& \mathrm{H}$ that the argument is problematic. But if we think that convincing people that the argument is problematic can play a role in changing their behaviour, we should consider what response is most convincing. We have suggested here that two such strategies are worth considering: questioning the notion of moral superiority on which the argument relies, and revealing the argument to be an instance of the naturalistic fallacy.

\section{References}

Chapman, C.A. and Huffman, M.A. (2018) Why do we want to think humans are different?. Animal Sentience 23(1)

Hume, D. (1739/2000) A Treatise of Human Nature. D. Fate Norton and M. J. Norton, eds. Oxford University Press.

lotchev, I.B. and Costa, K.M. (2019) Animal cognition: Quantity has a quality of its own. Animal Sentience 23(44)

Johannsen, K. (2019) Are some animals also moral agents?. Animal Sentience 23(27)

Juergens, U.M. (2018) Human and nonhuman animals: Equals in uniqueness. Animal Sentience 23(2)

Ng, Y-K. (2019) Human superiority is obvious but does not justify cruelty. Animal Sentience 23(36)

Paez, E. (2019) Humans may be unique and superior - and that is irrelevant. Animal Sentience 23(26)

Sachs, B. (2011) The status of moral status. Pacific Philosophical Quarterly 92(1)

Sachs, B. (2018) Explaining Right and Wrong: A New Moral Pluralism and its Implications. New York: Routledge.

Sinclair, N. (Ed.) (2018) The Naturalistic Fallacy. Cambridge University Press.

Vonk, J. (2019) Unique in degree not kindness. Animal Sentience 23(21)

Wilson, M.L. and Lehman, C.L. (2019) Humans: Uniquely responsible for causing conservation problems, uniquely capable of solving them. Animal Sentience 23(19)

Woodruff, M.L. (2019) Sentience is the foundation of animal rights. Animal Sentience 23(18) 